\title{
Validated Stability Indicating RP-HPLC Method for Simultaneous Estimation of Codeine Phosphate and Chlorpheniramine Maleate from Their Combined Liquid Dosage Form
}

\author{
Ramakrishna Kommana and Praveen Basappa \\ Department of Pharmaceutical Analysis and Quality Assurance, Gokaraju Rangaraju College of Pharmacy, Hyderabad 500 090, India
}

Correspondence should be addressed to Ramakrishna Kommana; rkkommana@gmail.com

Received 25 January 2013; Revised 25 February 2013; Accepted 26 February 2013

Academic Editor: Irene Panderi

Copyright (C) 2013 R. Kommana and P. Basappa. This is an open access article distributed under the Creative Commons Attribution License, which permits unrestricted use, distribution, and reproduction in any medium, provided the original work is properly cited.

The present paper describes the development of quick stability indicating RP-HPLC method for the simultaneous estimation of codeine phosphate and chlorpheniramine maleate in the presence of its degradation products, generated from forced degradation studies. The developed method separates codeine phosphate and chlorpheniramine maleate in impurities/degradation products. Codeine phosphate and chlorpheniramine maleate and their combination drug product were exposed to acid, base, oxidation, dry heat, and photolytic stress conditions, and the stressed samples were analysed by proposed method. The proposed HPLC method utilizes the Shimadzu HPLC system on a Phenomenex $\mathrm{C}_{18}$ column $(250 \mathrm{~mm} \times 4.6 \mathrm{~mm}, 5 \mu)$ using a mixture of $1 \% o$-phosphoric acid in water : acetonitrile : methanol $(78: 10: 12)$ mobile phase with $\mathrm{pH}$ adjusted to 3.0 in an isocratic elution mode at a flow rate of $1 \mathrm{~mL} / \mathrm{min}$, at $23^{\circ} \mathrm{C}$ with a load of $20 \mu \mathrm{L}$. The detection was carried out at $254 \mathrm{~nm}$. The retention time of codeine phosphate and chlorpheniramine maleate was found to be around $3.47 \mathrm{~min}$ and $9.45 \mathrm{~min}$, respectively. The method has been validated with respect to linearity, robustness, precision, accuracy, limit of detection (LOD), and limit of quantification (LOQ). The developed validated stability indicating HPLC method was found to be simple, accurate, and reproducible for the determination of instability of these drugs in bulk and commercial products.

\section{Introduction}

Codeine phosphate (CP) chemically is 7,8-didehydro-4, 5-epoxy-3-methoxy-17-methylmorphinan-6-ol dihydrogen phosphate hemihydrate [1], an alkaloid occurring in Papaver somniferum or obtained from morphine by methylation. The structure of CP is shown in Figure 1(a). It acts as a narcotic analgesic.

Chlorpheniramine maleate (CPM) chemically is (RS)-3(4-chlorophenyl)-3-(pyrid-2-yl) propyl-dimethylamine hydrogen maleate [1] as shown in Figure 1(b). Chlorpheniramine maleate is a first generation alkylamine antihistamine used in the prevention of the symptoms of allergic conditions such as rhinitis and urticaria.

The literature survey reveals that many analytical methods are reported for the determination of CP and CPM indi- vidually and in combination. The literature survey revealed spectroscopic [2-5] and chromatographic [6-20] methods.

The stability of a drug dosage form refers to the ability of a particular form to maintain its physical, chemical, therapeutic, and toxicological specification presented in the monograph on identity, strength, quality, and purity. The stability of a drug product should ordinarily be demonstrated by its manufacturer by methods appropriate for the purpose. Obviously, a stability testing problem is never simple. Stability testing is an important part of the process of drug product development. The purpose of the stability testing is to provide evidence on how the quality of a drug substance or drug product varies with time under the influence of a variety of environmental factors, such as temperature, humidity, and sun light, and enables recommendation of storage conditions, retest periods, and shelf lives to be established. 


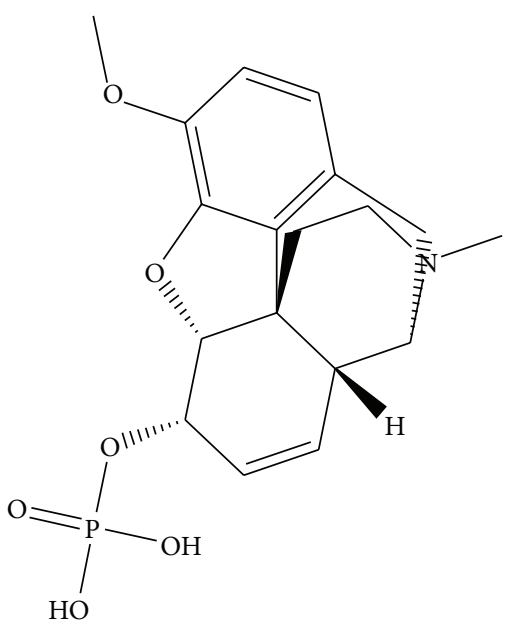

(a)<smiles>O=C(O)/C=C\C(=O)O</smiles>

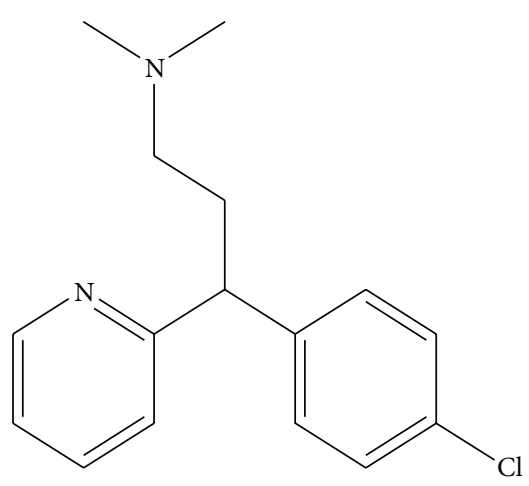

(b)

FIGURE 1: Chemical structure of (a) codeine phosphate and (b) chlorpheniramine maleate.

Two main aspects of a drug product that play an important role in shelf life determination are the assay of the active drug and the degradation products generated during the stability study. The drug product in a stability test sample needs to be determined using a stability indicating method, as recommended by the International Conference on Harmonization (ICH) guidelines [21].

The literature survey reveals that many analytical methods are reported for the determination of $\mathrm{CP}$ and $\mathrm{CPM}$ individually and in combination. The combination of $\mathrm{CP}$ and CPM in liquid dosage form has not been reported in any pharmacopoeia. So far, no RP-HPLC stability indicating method has been reported for the simultaneous estimation of $\mathrm{CP}$ and CPM in liquid pharmaceutical formulation. Therefore, it is necessary to develop a new rapid and stability indicating method for simultaneous estimation of two compounds (CP and CPM) in liquid pharmaceutical formulation. The proposed method is able to separate CP and CPM with each other and from its impurities/degradation products. Thereafter, this method was validated as per ICH guidelines and successfully applied for separation and quantification of all compounds of interest in the liquid pharmaceutical formulation.

Codeine phosphate impurities (CP-IMPs); A, B, C, and D, are official in British Pharmacopoeia [22]. Chlorpheniramine Maleate impurities (CPM-IMPs); A, B, C, and D, are also official in British Pharmacopoeia [23].

The aim of this work was to develop a quick stability indicating RP-HPLC method for the simultaneous estimation of codeine phosphate and chlorpheniramine maleate in the presence of its degradation products, generated from forced degradation studies. The stability indicating power of the method was established by comparing the chromatograms obtained under optimized conditions before forced degradation with those after forced degradation via acidic, basic, oxidative, thermal, and photolytic stress conditions.

\section{Experimental}

2.1. Materials and Reagents. Methanol, water, acetonitrile, and $o$-phosphoric acid used were of HPLC (Merck, Mumbai, India). All the glass wares used were of standard quality. Reference samples of CP and CPM were obtained as gift samples from AstraZeneca Pharma India Ltd. Bangalore, India. Liquid dosage form (oral syrup) containing CP $10 \mathrm{mg}$ and CPM $4 \mathrm{mg}$ was used as the sample during the method development process.

Chromatographic Equipments and Conditions. A Shimadzu Prominence binary gradient, a high pressure liquid chromatographic instrument was used for the analysis. The instrument was provided with a Phenomenex $\mathrm{C}_{18}(250 \times 4.6 \mathrm{~mm}$, $5 \mu$ ), an LC $20 \mathrm{AD}$ pump and an SPD 20A UV-visible detector were employed. A $20 \mu \mathrm{L}$ Hamilton syringe was used for sample injection. Data acquisition was done by using LC solutions software.

Mobile Phase Preparation. The mixture of acetonitrile, methanol, and 1\%o-phosphoric acid in the ratio 78:10:12 was used as a mobile phase with $\mathrm{pH}$ adjusted to 3.0. The mobile phase was filtered through $0.45 \mu$ membrane. The mobile phase was ultrasonicated for $5 \mathrm{~min}$ to degas the mixture and then used.

Instrumental Parameters. The separation was done on Phenomenex $\mathrm{C}_{18}$ column $(250 \times 4.6 \mathrm{~mm}, 5 \mu)$. The flow rate of mobile phase was maintained at $1 \mathrm{~mL} / \mathrm{min}$, and the detection was carried out at $254 \mathrm{~nm}$. All determinations were performed at a constant column temperature of $23^{\circ} \mathrm{C}$ with a load of $20 \mu \mathrm{L}$. The retention time of CP and CPM was observed at 3.47 and $9.45 \mathrm{~min}$.

Stress Study. All the stress decomposition studies were performed at a concentration of $50 \mu \mathrm{g} / \mathrm{mL}$ in mobile phase. 
Acid hydrolysis was performed in $0.1 \mathrm{M}$ hydrochloric acid. The study in alkaline condition was carried out in $0.1 \mathrm{M}$ sodium hydroxide. Oxidative studies were carried out in $10 \%$ hydrogen peroxide. For photolytic degradation studies, pure drug that is a solid state was exposed to UV lamp in UV cabinet at $254 \mathrm{~nm}$. Additionally, the drug powder was exposed to dry heat at $105^{\circ} \mathrm{C}$. Samples were withdrawn at appropriate time, cooled and neutralized by adding base or acid, and subjected to RP- HPLC analysis after suitable dilution.

\subsection{Preparation of Standard Solutions and Calibration Graphs.} Standard Stock Solutions of CP and CPM were prepared in mobile phase $(1 \mathrm{mg} / \mathrm{mL})$.

From CP solution, $10 \mathrm{~mL}$ was taken and diluted to $100 \mathrm{~mL}$ with mobile phase $(100 \mu \mathrm{g} / \mathrm{mL})$. From CPM solution, $2 \mathrm{~mL}$ was taken and diluted to $100 \mathrm{~mL}$ with mobile phase $(20 \mu \mathrm{g} / \mathrm{mL})$. Calibration standards at five levels were prepared by appropriately mixing and further diluting stock standard solutions in the concentration range of $50-150 \mu \mathrm{g} / \mathrm{mL}$ for $\mathrm{CP}$ and $10-60 \mu \mathrm{g} / \mathrm{mL}$ for CPM. Samples in triplicates were made for each concentration, and peak areas were plotted against the corresponding concentrations to obtain the calibration graph. The regression equation was derived using mean peak area concentration data, and the concentration of the unknown was computed from the regression equation.

2.3. Preparation of Placebo Solution. An accurately weighed 2 gm of placebo solution was taken into the $100 \mathrm{~mL}$ volumetric flak. About $70 \mathrm{~mL}$ of diluent was added to this volumetric flask and sonicated in an ultrasonic bath for $5 \mathrm{~min}$. This solution was then diluted up to the mark with diluent and mixed well. It is then filtered through $0.22 \mu \mathrm{m}$ PVDF syringe filter, and the filtrate was collected after discarding first few milliliters.

\subsection{Assay Procedure for Syrup (Combined Formulation of CP} and $(P M)$. Syrup equivalent to $10 \mathrm{mg}$ and $4 \mathrm{mg}$ of $\mathrm{CP}$ and CPM was taken in a $100 \mathrm{~mL}$ volumetric flask. Volume was made to the mark with mobile phase. The flask was sonicated for $5 \mathrm{~min}$. The above solution was filtered using $0.22 \mu \mathrm{m}$ PVDF syringe filter, and the filtrate was collected after discarding the first few milliliters. The solution is then injected under above chromatographic conditions, and peak areas were measured. The assay procedure was made triplicate, and weight of sample taken for assay was calculated and summarised in Table 1.

\subsection{Method Validation Procedure}

2.5.1. Selectivity. The selectivity of the method was evaluated with regard to interference due to the presence of any other excipients. This shows that drugs were clearly separated from its excipients. Thus, the HPLC method presented in this study was found to be selective, depicted in Figure 2.

2.5.2. Linearity. The linearity of calibration curves (peak area ratio versus concentration) in pure solution was checked over

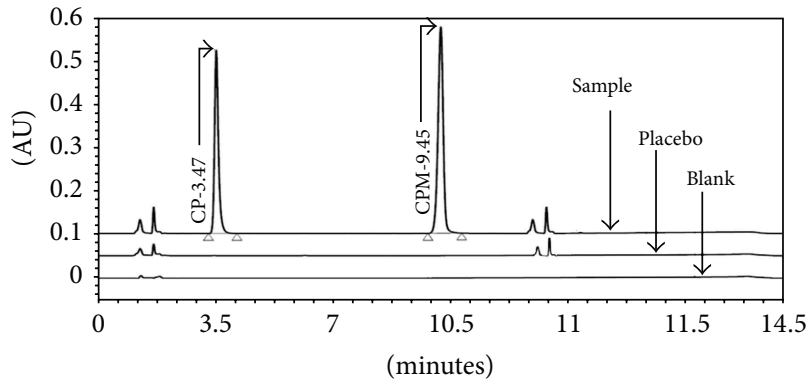

FIgURE 2: Overlay chromatograms of blank, placebo, and sample preparation.

the concentration ranges of about $50-150 \mu \mathrm{g} / \mathrm{mL}$ for $\mathrm{CP}$ and $10-60 \mu \mathrm{g} / \mathrm{mL}$ for CPM. Hence, the regression line relating standard concentrations of drug using regression analysis, the calibration curves were linear in the studied range.

2.5.3. Precision. Three injections of same concentration were given on the same day, and these studies were also repeated on different days to determine interday precision.

2.5.4. Accuracy. The accuracy of the method was validated by recovery studies and was found to be significant under specification limits.

2.5.5. Limit of Detection (LOD) and Limit of Quantification (LOQ). Limit of detection was calculated by using the formula:

$$
\begin{aligned}
& \mathrm{LOD}=3.3 \mathrm{SD} / \mathrm{S} \\
& \mathrm{SD}=\text { standard deviation of the response } \\
& S=\text { slope of calibration curve of the analyte. }
\end{aligned}
$$

Limit of quantification was calculated by using the formula:

$$
\begin{aligned}
& \text { LOQ }=10 \mathrm{SD} / S \\
& \mathrm{SD}=\text { standard deviation of the response } \\
& S=\text { slope of calibration curve of the analyte. }
\end{aligned}
$$

2.5.6. Robustness. To determine robustness of the method the experimental conditions were deliberately changed. The flow rate of the mobile phase, $\mathrm{pH}$ of the mobile phase, was varied parameters. The study was performed on same day. The area obtained from each variation was compared with that obtained under optimized conditions.

2.5.7. Filter Compatibility. Sample compatibility was performed for nylon $0.22 \mu \mathrm{m}$ syringe filter (Pall life sciences) and PVDF $0.22 \mu \mathrm{m}$ syringe filter (Millipore). To compare the filter compatibility in proposed analytical method, filtration recovery experiment was carried out by sample filtration technique. Sample was filtered through both syringe filters, and percentage assay was determined and compared against centrifuged sample. Sample solution was not showing any 
TABLE 1: Assay of formulation.

\begin{tabular}{lcccr}
\hline Formulation & Drug & Label claim & $\begin{array}{c}\text { Amount found, (mg) } \\
\text { AM } \pm \text { SD }^{*}\end{array}$ & \% Assay RSD \\
\hline Coscodin & CP & $10 \mathrm{mg}$ & $10.01 \pm 0.05$ & 100.1 \\
& CPM & $4 \mathrm{mg}$ & $3.99 \pm 0.006$ & 9.55 \\
Mit's Linctus Codeinae Co. & $\mathrm{CP}$ & $10 \mathrm{mg}$ & $10.05 \pm 0.05$ & 0.16 \\
& $\mathrm{CPM}$ & $4 \mathrm{mg}$ & $4.11 \pm 0.006$ & 100.5 \\
\hline
\end{tabular}

${ }^{*} n=6$.

TABLE 2: Filter compatibility results (assay $\% \mathrm{w} / \mathrm{w}$ ).

\begin{tabular}{lccc}
\hline Compound & Centrifuged & PVDF filter $0.22 \mu \mathrm{m}$ (Millipore) & Nylon filter $0.22 \mu \mathrm{m}$ (Macherey-Nagel) \\
\hline CP & 99.5 & 99.3 & 99.3 \\
CPM & 100.3 & 100.5 & 100.4 \\
\hline
\end{tabular}

TABLE 3: Optimized chromatographic conditions.

\begin{tabular}{ll}
\hline Parameter & Optimized condition \\
\hline Chromatograph & Shimadzu HPLC with UV detector \\
Column & $\begin{array}{l}\text { Phenomenex } \mathrm{C}_{18} \text { column }(250 \times 4.6 \mathrm{~mm}, \\
\end{array}$ \\
& $\begin{array}{l}1 \% o \text {-phosphoric acid in water, } \mathrm{pH} \\
\text { adjusted to } 3.0: \text { acetonitrile }: \text { methanol } \\
(78: 10: 12)\end{array}$ \\
Mobile phase & $1 \mathrm{~mL} / \mathrm{min}$ \\
Flow rate & $\mathrm{UV}$ at $254 \mathrm{~nm}$ \\
Detection & $20 \mu \mathrm{L}$ \\
Injection volume & $23^{\circ} \mathrm{C}$ \\
Column temperature
\end{tabular}

significant changes in assay percentage with respect to centrifuged sample. Percentage assay results are presented. The result difference in \% assay was not observed more than \pm 0.5 , which indicates that both syringe filters are having a good compatibility with sample solution. The filter compatibility results were given in Table 2 .

2.5.8. Solution Stability. Stability of sample solution was established by the storage of sample solution at $25^{\circ} \mathrm{C}$ for $24 \mathrm{hr}$. Sample solution was reanalyzed after 12 and $24 \mathrm{hr}$ time intervals, and assay was determined for the compounds (CP and CPM) and compared against fresh sample. Sample solution did not show any appreciable change in assay value when stored at ambient temperature up to $24 \mathrm{hr}$. The results from solution stability experiments confirmed that sample was stable up to $24 \mathrm{hr}$ during assay determination.

2.6. Forced Degradation Studies of API and Formulation. Stress studies were carried by using $50 \mu \mathrm{g} / \mathrm{mL}$ of each solution in different conditions. Acidic and alkaline hydrolysis was carried out in $0.1 \mathrm{M}$ hydrochloric acid $(\mathrm{HCl})$ and $0.1 \mathrm{M}$ sodium hydroxide $(\mathrm{NaOH})$.

The oxidative study was carried out in $10 \%$ hydrogen peroxide $\left(\mathrm{H}_{2} \mathrm{O}_{2}\right)$ for $24 \mathrm{hr}$.

Photolytic studies on the drug were carried out by the exposure to UV lamp in UV cabinet at $254 \mathrm{~nm}$.
For thermal stress testing, both the drugs were spread in petridish and placed in the oven at $105^{\circ} \mathrm{C}$. Samples were withdrawn periodically and subjected to analysis after suitable dilution.

\section{Results and Discussion}

The main objective of the RP-HPLC method was to determine a validated stability indicating method for the estimation of $\mathrm{CP}$ and CPM simultaneously in liquid pharmaceutical formulation and to obtain well-resolved peaks of CP, CPM, and impurities/degradants. The method should be able to determine degradants/impurities and assay of two compounds in single run and should be accurate, reproducible, robust, stabile indicating, filter compatible, linear, free of interference from blank/placebo/impurities/degradation products, and straightforward enough for routine use in quality control laboratory.

3.1. Method Development and Optimization. Different chromatographic conditions were experimented to achieve better efficiency of the chromatographic system. Parameters such as mobile phase composition, wavelength of detection, column, column temperature and $\mathrm{pH}$ of mobile phase were optimized. Several proportions of buffer and solvents were evaluated in order to obtain suitable composition of mobile phase. Different composition of mobile phases containing a mixture $(\mathrm{v} / \mathrm{v})$ of $1 \% o$-phosphoric acid in water, acetonitrile, and methanol was tried, but the mixture of $1 \% o$-phosphoric acid in water, $\mathrm{pH}$ adjusted to 3.0 , acetonitrile, and methanol in the ratio $78: 10: 12$ was selected as optimal for obtaining welldefined and well-resolved peaks of CP and CPM at a flow rate of $1 \mathrm{~mL} / \mathrm{min}$ on a Phenomenex $\mathrm{C}_{18}$ column. $254 \mathrm{~nm}$ was selected as the optimum wavelength for detection and quantitation, at which best detector response for both $\mathrm{CP}$ and CPM was obtained. The mean retention time for CP and CPM was found to be $3.47 \mathrm{~min}$ and $9.45 \mathrm{~min}$, respectively. The summary of chromatographic condition is given in Table 3.

3.2. Stability Studies. All forced degradation studies were analysed at $50 \mu \mathrm{g} / \mathrm{mL}$ concentration level. The drug stability 


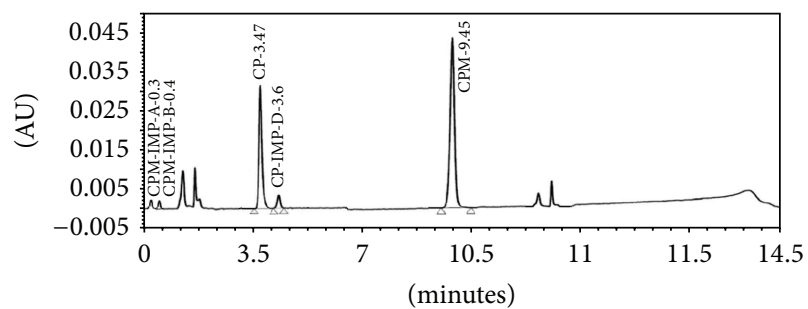

(a)

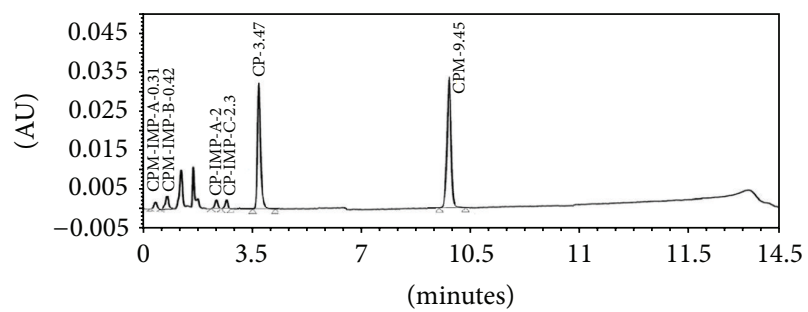

(c)

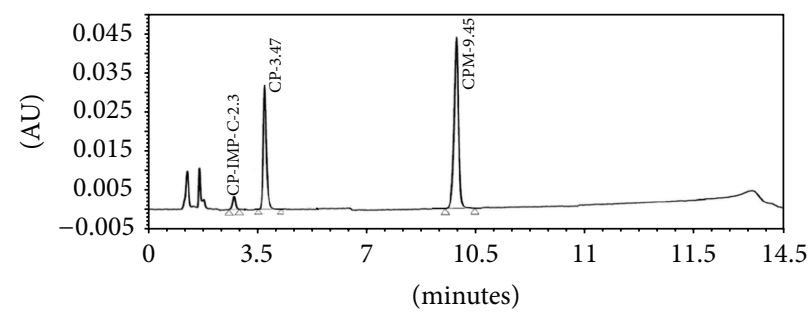

(b)

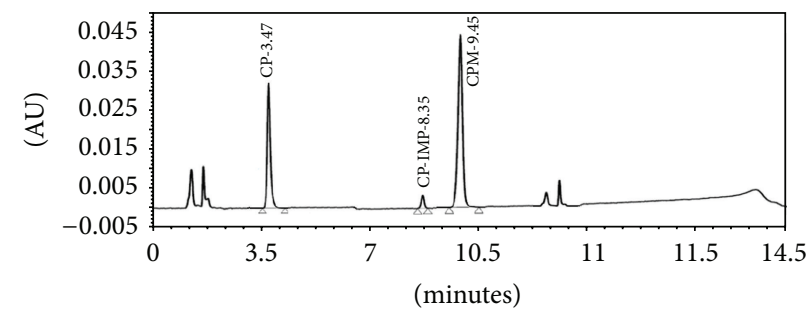

(d)

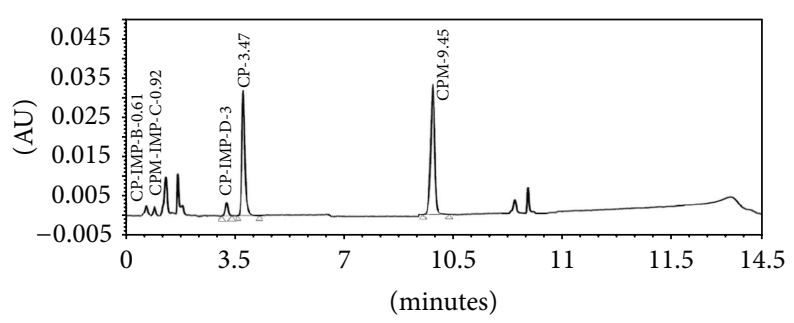

(e)

Figure 3: (a) Acid degradation, (b) base degradation, (c) oxidative degradation, (d) photodegradation, and (e) thermal degradation.

TABLE 4: Solution stability results.

\begin{tabular}{lcc}
\hline Time intervals & CP & CPM \\
\hline \% assay initial & 100.3 & 99.5 \\
$\%$ assay after $12 \mathrm{hrs}$ & 100.7 & 99.6 \\
$\%$ assay after $24 \mathrm{hrs}$ & 100.4 & 99.3 \\
\hline
\end{tabular}

in pharmaceutical formulations is a function of storage conditions and chemical properties of the drug and its impurities. Conditions used in stability experiments should reflect situations likely to be encountered during actual sample handling and analysis. Stability data is required to show that the concentration and purity of analyte in sample at the analysis corresponds to the concentration and purity of the analyte at the time of sampling. CP and CPM were subjected to acid, alkaline, oxidative, photolytic, and dry heat stress conditions. The chromatograms obtained after subjecting to degradation are presented in Figures 3(a), 3(b), 3(c), 3(d), and 3(e).

3.3. Stability of Sample in Diluent. Drug stability in pharmaceutical formulations is a function of storage conditions and chemical properties of the drug and its impurities. Condition used in stability experiments should reflect situations likely to be encountered during actual sample handling and analysis.
Stability data is required to show that the concentration and purity of analyte in the sample at the analysis corresponds to the concentration and purity of analyte at the time of sampling. Stability of sample solution was established by storage of sample solution at ambient temperature $\left(25^{\circ} \mathrm{C}\right)$ for $24 \mathrm{hr}$. Sample solution was reanalyzed after 12 and $24 \mathrm{hr}$ time intervals, and assay was determined for the compounds (CP and CPM) and compared against fresh sample. Sample solution did not show any appreciable change in assay value when stored at ambient temperature up to $24 \mathrm{hr}$, which are presented in Table 4 . The results from solution stability experiments confirmed that the sample was stable up to $24 \mathrm{hr}$ during assay determination.

Validation of the Method. The described method for the assay of CP and CPM has been validated as per current ICH Q2 (R1).

3.4. Linearity. Calibration curves were obtained for $\mathrm{CP}$ and CPM from which the linear regression equation was computed and found to be $y=104033 x-777923, r^{2}=0.9985$ for CP and $y=221251 x-956140, r^{2}=0.9991$ for CPM.

3.5. Accuracy and Precision. The percent standard error which is an indicator of accuracy is $\leq 1.0$ and is indicative of high accuracy. The calculated percent relative standard 
TABLE 5: Result of accuracy studies.

\begin{tabular}{|c|c|c|c|c|c|}
\hline Name of drug & $\begin{array}{c}\text { Amount in sample } \\
(\mathrm{mg})\end{array}$ & $\begin{array}{l}\text { Amount of drug spiked in mg, } \\
(\% \text { recovery level })\end{array}$ & $\begin{array}{l}\text { Amount found, (mg) } \\
\qquad \mathrm{AM} \pm \mathrm{SD}^{*}\end{array}$ & $\% \mathrm{SE}$ & $\%$ RSD \\
\hline \multirow{3}{*}{$\mathrm{CP}$} & 20 & $16,(80 \%)$ & $36.37 \pm 0.06$ & 0.034 & 0.18 \\
\hline & 20 & $20,(100 \%)$ & $40.36 \pm 0.10$ & 0.057 & 0.25 \\
\hline & 20 & $24,(120 \%)$ & $44.55 \pm 0.11$ & 0.063 & 0.25 \\
\hline \multirow{3}{*}{ CPM } & 8 & $6.4,(80 \%)$ & $14.38 \pm 0.01$ & 0.005 & 0.13 \\
\hline & 8 & $8,(100 \%)$ & $15.98 \pm 0.06$ & 0.034 & 0.42 \\
\hline & 8 & $9.6,(120 \%)$ & $17.59 \pm 0.06$ & 0.034 & 0.38 \\
\hline
\end{tabular}

${ }^{*} n=3$.

TABLE 6: Results of precision studies.

\begin{tabular}{lcccc}
\hline Drug & Concentration $(\mu \mathrm{g} / \mathrm{mL})$ & $\begin{array}{c}\text { Intraday }(n=3) \\
\text { Measured concentration }(\mu \mathrm{g} / \mathrm{mL}) \\
\mathrm{AM} \pm \mathrm{SD}\end{array}$ & \% CV & $\begin{array}{c}\text { Interday }(n=3) \\
\text { Measured concentration }(\mu \mathrm{g} / \mathrm{mL}) \\
\mathrm{AM} \pm \mathrm{SD}\end{array}$ \\
\hline $\mathrm{CP}$ & 100 & $99.33 \pm 0.45$ & 0.45 & $99 \pm 0.45$ \\
$\mathrm{CPM}$ & 20 & $19.46 \pm 0.12$ & 0.64 & $19.58 \pm 0.1$ \\
\hline
\end{tabular}

TABLE 7: Robustness studies.

\begin{tabular}{lccc}
\hline Sl. no & Parameter & Modification & Retention time $(\mathrm{min})$ \\
\hline \multirow{2}{*}{1} & \multirow{2}{*}{ Flow rate } & $0.8 \mathrm{~mL} / \mathrm{min}$ & $3.2,9.13$ \\
& & $1.2 \mathrm{~mL} / \mathrm{min}$ & $3.31,9.32$ \\
2 & $\mathrm{pH}$ & 2.8 & $3.63,9.7$ \\
& & 3.2 & $3.3,8.9$ \\
\hline
\end{tabular}

TABLE 8: System suitability parameters.

\begin{tabular}{lccc}
\hline S. no. & Parameter & CP & CPM \\
\hline 1 & Retention time (min) & 3.47 & 9.45 \\
2 & Peak asymmetry & 1.0 & 1.0 \\
3 & Theoretical plates & 11100 & 17692 \\
4 & Resolution & 3.05 & 7.78 \\
5 & Limit of detection (LOD), $\mu \mathrm{g} / \mathrm{mL}$ & 2.263 & 0.756 \\
6 & Limit of quantification (LOQ), $\mu \mathrm{g} / \mathrm{mL}$ & 6.859 & 2.293 \\
\hline
\end{tabular}

deviation (\%RSD) can be considered to be satisfactory. The percentage RSD values were $<1 \%$. The results obtained for the evaluation of accuracy and precision of the method are compiled in Tables 5 and 6.

3.6. Robustness. The robustness of an analytical procedure is a measure of its capacity to remain unaffected by small, but deliberate variations in method parameters, and provides an indication of its reliability during normal usage. The results are summarized in Table 7.

3.7. Solution Stability. Stability of sample solution was established by the storage of sample solution at $25^{\circ} \mathrm{C}$ for $24 \mathrm{hr}$. Sample solution was reanalyzed after 12 and $24 \mathrm{hr}$ time intervals, and assay was determined for the compounds (CP and CPM) and compared against fresh sample. Sample solution did not show any appreciable change in assay value when stored at ambient temperature up to $24 \mathrm{hr}$. The results from solution stability experiments confirmed that sample was stable up to $24 \mathrm{hr}$ during the assay determination.

3.8. System Suitability. The system suitability was carried out after the method development and validation have been completed. For this, parameters like theoretical plates, resolution, retention time, and peak symmetry of samples were measured and shown in Table 8.

\section{Conclusion}

The reported RP-HPLC method was proved to be simple, rapid, and reproducible. The validation data indicate good precision, accuracy, and reliability of the method. The developed method offers several advantages in terms of simplicity in mobile phase, isocratic mode of elution, easy sample preparation steps, and comparative short run time which makes the method specific and reliable for its intended use in simultaneous determination of codeine phosphate and chlorpheniramine maleate in liquid oral dosage form. Quick stability indicating RP-HPLC method was developed for the simultaneous estimation of codeine phosphate and chlorpheniramine maleate in the presence of its degradation products, generated from forced degradation studies. The developed method separates codeine phosphate chlorpheniramine maleate in impurities/degradation products. There were no reported stability indicating methods for this combination of drugs in liquid dosage form; hence, this method has an advantage of being unique and novel.

\section{Conflict of Interests}

The authors declared that they have no conflict of interests or financial gains in mentioning the companies names or trademarks. 


\section{Acknowledgment}

The authors acknowledge the management for providing necessary facilities.

\section{References}

[1] USP-NF, The Official Compendia of Standards, USP Convention, INC., Rock wiley, 2003.

[2] R. Sawant, R. Joshi, P. Lanke, and L. Bhangale, "Simultaneous estimation \& validation of paracetamol, phenylephrine hydrochloride and chlorpheniramine maleate in tablets by spectrophotometric method," Journal of Pharmaceutical Research and Health Care, vol. 3, no. 2, pp. 23-28, 2011.

[3] D. T. T. An and V. D. Hoang, "Simultaneous determination of paracetamol and codeine phosphate in combined tablets by first-order derivative and ratio spectra first-order derivative UV spectrophotometry," Asian Journal For Research in Chemistry, vol. 2, no. 2, pp. 143-147, 2009.

[4] B. Praveen, M. Padmaja, and R. K. Krishna, "Development and validation of UV spectrophotometric method for simultaneous estimation of codeine phosphate and chlorpheniramine maleate in combined liquid dosage form," International Journal of Pharmacy and Technology, vol. 3, no. 3, pp. 3390-3400, 2011.

[5] A. Biswas, "Spectrophotometric method for determination of chlorpheniramine maleate in pharmaceutical preparations in the presence of codeine phosphate and ephedrine hydrochloride," Analyst, vol. 105, no. 1249, pp. 353-358, 1980.

[6] U. R. Mallu, V. Bobbarala, and S. Penumajji, "Analysis of cough and analgesic range of pharmaceutical active ingredients using RP-HPLC method," International Journal of Pharma and Bio Sciences, vol. 2, no. 3, pp. 439-452, 2011.

[7] A. Manassra, M. Khamis, M. el-Dakiky, Z. Abdel-Qader, and F. Al-Rimawi, "Simultaneous HPLC analysis of pseudophedrine hydrochloride, codeine phosphate, and triprolidine hydrochloride in liquid dosage forms," Journal of Pharmaceutical and Biomedical Analysis, vol. 51, no. 4, pp. 991-993, 2010.

[8] M. Maithani, R. Raturi, V. Gautam et al., "Development and validation of a RP-HPLC method for the determination of chlorpheniramine maleate and phenylephrine in pharmaceutical dosage form," International Journal of Comprehensive Pharmacy, vol. 1, no. 5, pp. 1-4, 2010.

[9] D. J. Hood and H. Y. Cheung, "A chromatographic method for rapid and simultaneous analysis of codeine phosphate, ephedrine $\mathrm{HCl}$ and chlorpheniramine maleate in cough-cold syrup formulation," Journal of Pharmaceutical and Biomedical Analysis, vol. 30, no. 5, pp. 1595-1601, 2003.

[10] N. Erk and M. Kartal, "Simultaneous high performance liquid chromatographic and derivative ratio spectra spectrophotometry determination of chlorpheniramine maleate and phenylephrine hydrochloride," Farmaco, vol. 53, no. 8-9, pp. 617-622, 1998.

[11] G. Santoni, L. Fabbri, P. Gratteri, G. Renzi, and S. Pinzauti, "Simultaneous determination of aspirin, codeine phosphate and propyphenazone in tablets by reversed-phase highperformance liquid chromatography," International Journal of Pharmaceutics, vol. 80, no. 2-3, pp. 263-266, 1992.

[12] W. R. Sisco, C. T. Rittenhouse, and W. M. Maggio, "The rapid quantitative analysis of codeine phosphate drug substance by reversed-phase high-performance liquid chromatography," Chromatographia, vol. 20, no. 5, pp. 289-292, 1985.
[13] S. Chittrakarn, P. Penjamras, and N. Keawpradub, "Quantitative analysis of mitragynine, codeine, caffeine, chlorpheniramine and phenylephrine in a kratom (Mitragyna speciosa Korth.) cocktail using high-performance liquid chromatography," Forensic Science International, vol. 217, no. 1-3, pp. 81-86, 2012.

[14] Z. Hu, Q. Zou, J. Tian, L. Sun, and Z. Zhang, "Simultaneous determination of codeine, ephedrine, guaiphenesin and chlorpheniramine in beagle dog plasma using high performance liquid chromatography coupled with tandem mass spectrometric detection: application to a bioequivalence study," Journal of Chromatography B, vol. 879, no. 32, pp. 3937-3942, 2011.

[15] D. J. Hood and H. Y. Cheung, "A chromatographic method for rapid and simultaneous analysis of codeine phosphate, ephedrine $\mathrm{HCl}$ and chlorpheniramine maleate in cough-cold syrup formulation," Journal of Pharmaceutical and Biomedical Analysis, vol. 30, no. 5, pp. 1595-1601, 2003.

[16] R. Ragonese, M. Mulholland, and J. Kalman, "Full and fractionated experimental designs for robustness testing in the high-performance liquid chromatographic analysis of codeine phosphate, pseudoephedrine hydrochloride and chlorpheniramine maleate in a pharmaceutical preparation," Journal of Chromatography A, vol. 870, no. 1-2, pp. 45-51, 2000.

[17] K. P. R. Shenoy, K. S. Krishnamurthy, and M. V. Vinod, "Simultaneous determination of codeine phosphate and chlorpheniramine maleate in formulation by reverse phase liquid chromatography," Indian Drugs, vol. 36, no. 8, pp. 513-516, 1999.

[18] R. N. Raju, P. Srilakshmi, and M. Muralee Krishna, "Simultaneous determination of chlorpheniramine maleate, ephedrine hydrochloride and codeine phosphate in cough syrups by reverse phase high performance liquid chromatography," Indian Drugs, vol. 29, no. 9, pp. 408-411, 1992.

[19] H. Al-Kaysi and T. H. N. M. S. Salem, "Simultaneous quantitative determination of codeine phosphate, chlorpheniramine maleate, phenylephrine hydrochloride, and acetaminophen in pharmaceutical dosage forms using thin layer chromatography densitometry," Analytical Letters, vol. 19, no. 7-8, pp. 915-924, 1986.

[20] K. Masumoto, Y. Tashiro, and K. Matsumoto, "Simultaneous determination of codeine and chlorpheniramine in human plasma by capillary column gas chromatography," Journal of Chromatography, vol. 381, no. 2, pp. 323-329, 1986.

[21] International Conference on Harmonization, Validation of Analytical Procedure, Text and Methododlogy Q2 (R1), IFMA, Geneva, Switzerland, 2005.

[22] Codeine Phosphate, vol. 584 of (Ph Eur monograph 0074), British Pharmacopeia, 2008.

[23] Chlorpheniramine Maleate, vol. 498 of (Ph Eur monograph 0386), British Pharmacopeia, 2008. 

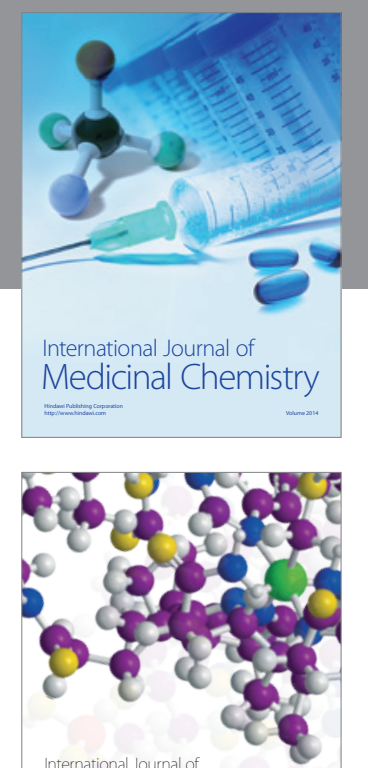

\section{Carbohydrate} Chemistry

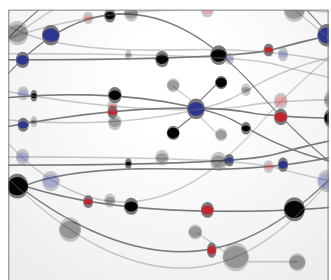

The Scientific World Journal
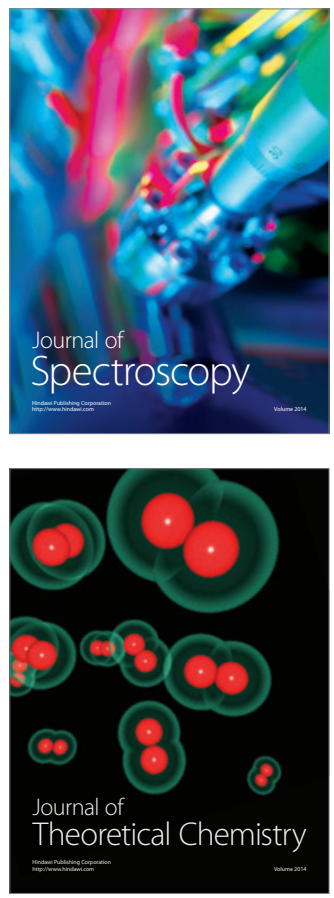
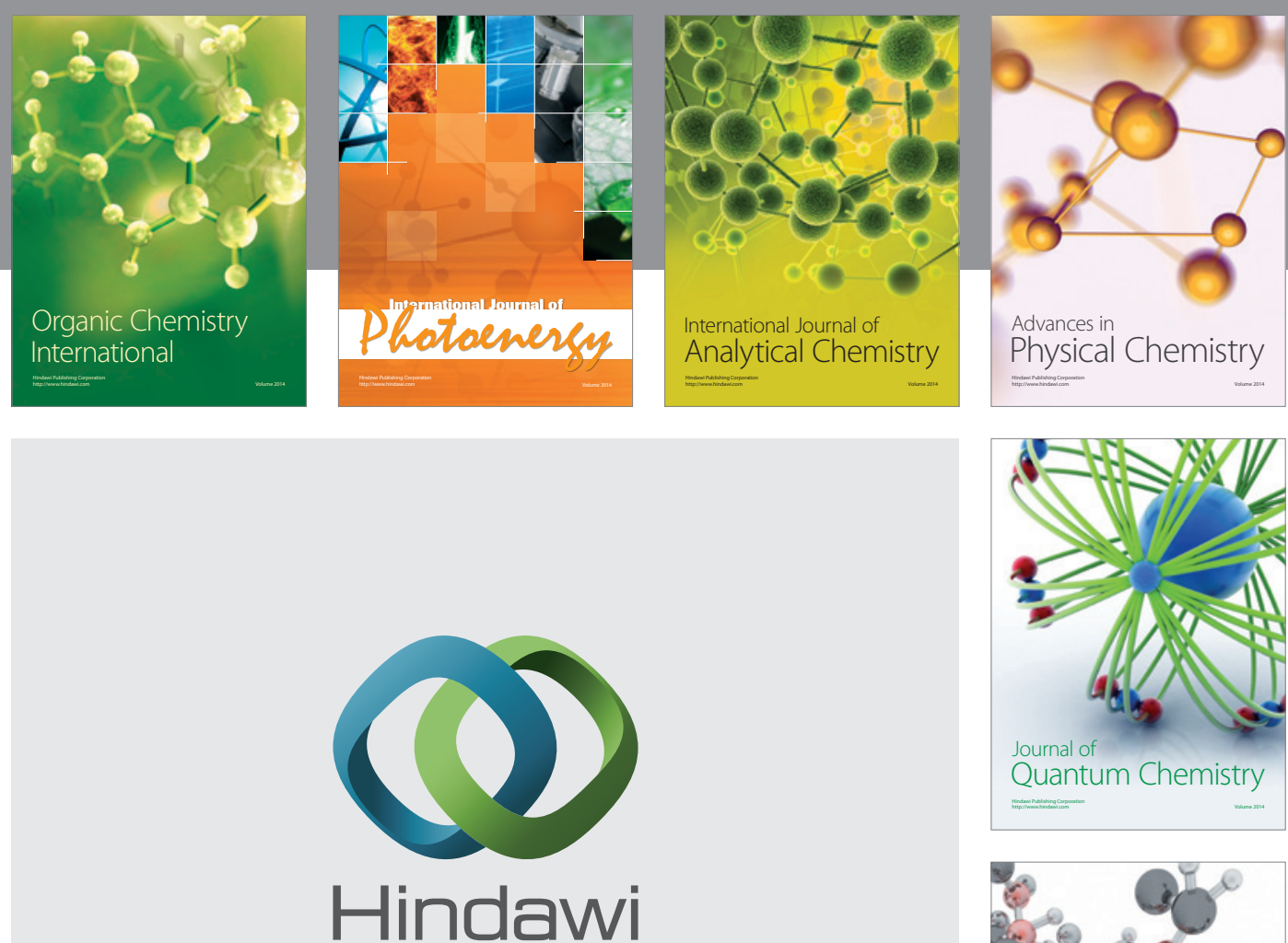

Submit your manuscripts at

http://www.hindawi.com

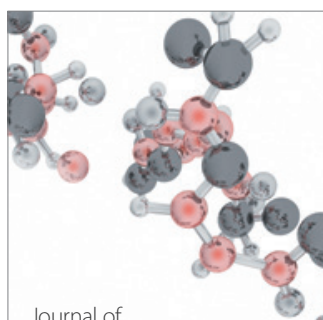

Analytical Methods

in Chemistry

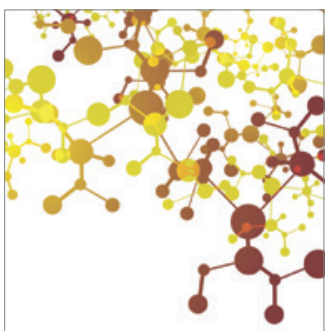

Journal of

Applied Chemistry

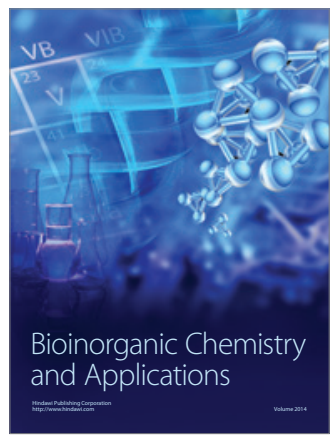

Inorganic Chemistry
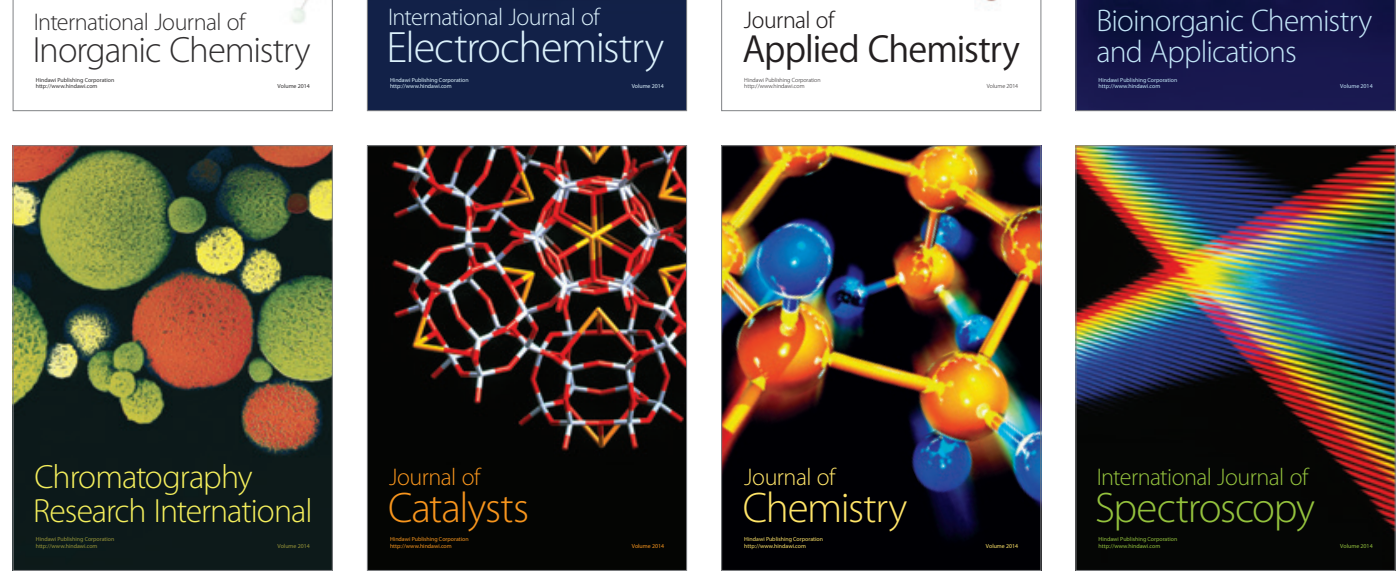